\title{
ANÁLISE DESCRITIVA DE NASCENTES DO RIO SÃO FRANCISCO, NO CHAPADÃO DIAMANTE, NA SERRA DA CANASTRA-MG
}

\author{
Giliander Allan da Silva ${ }^{(1)}$, Renato Emanuel Silva ${ }^{(2),}$ Silvio Carlos Rodrigues ${ }^{(3)}$ \\ (1) Aluno Programa de Pós-graduação em Geografia/Universidade Federal de Uberlândia, gili.franca@ hotmail.com \\ (2) Aluno Programa de Pós-graduação em Geografia/Universidade Federal de Uberlândia, renato.logan@ gmail.com \\ (3) Professor Doutor do Instituto de Geografia/ Universidade Federal de Uberlândia, silgel@ufu.br
}

\section{EIXO: BACIAS HIDROGRÁFICAS E RECURSOS HÍDRICOS: ANÁLISE, PLANEJAMENTO E GESTÃO}

\begin{abstract}
Resumo
O estudo se desenvolve no Chapadão Diamante na Serra da Canastra, sudoeste mineiro. Como parte de uma pesquisa mais detalhada, foi realizada uma análise descritiva de quatro nascentes (GP1, GP2, GP3 e GP4) que compõem um agrupamento de nascentes do Rio São Francisco, acompanhada de medição de vazão destes canais de primeira ordem. Com uso de um recipiente graduado e cronometro obteve os volumes de água por tempo que exfiltra em cada nascente, num cenário de estação chuvosa. As características geológicas, de vegetação e da cobertura superficial influenciam sobremaneira no volume exfiltrado, sendo que, 3 nascentes têm vazão entre 29 e $55,3 \mathrm{~mL} / \mathrm{s}$, classificadas como de sétima magnitude e 1, a GP1 é de oitava magnitude com vazão de $6,2 \mathrm{~mL} / \mathrm{s}$. É de grande importância aprofundar nos estudos nas áreas de cabeceiras de drenagem, pois são regiões que impactam diretamente no regime hidrológico de todo sistema à jusante.
\end{abstract}

Palavras chave: infiltração; exfiltração; Serra da Canastra; vazão.

\section{Introdução}

A água, além de elemento fundamental para a vida, interage com os recursos naturais tornando-se agente modelador de relevo (GOERL; KOBIYAMA; SANTOS, 2012), atuando na pedogênese, na erosão, no transporte e deposição de sedimentos.

Existem algumas áreas que possuem grande importância para o homem devido a características geomorfológicas particulares. Desta maneira, destaca-se a Serra da Canastra, cujos eventos terrígenos possibilitaram esta área ser um orógeno limítrofe entre duas importantes bacias hidrográficas brasileiras, definindo os caminhos pelos quais as águas, oriundas deste relevo, devem verter. Este fator é suficiente para que ali se desenvolva pesquisas e amplie o conhecimento humano sobre o comportamento da água em superfície e subsuperfície.

Observada a sua importância, por meio do decreto $\mathrm{n}^{\mathrm{o}}$ 70.335, de 03 de abril de 1972, foi criado o Parque Nacional da Serra da Canastra (PNSC). Com área abrangendo 2.000 quilômetros quadrados, distribuindose em parte dos municípios de Sacramento, São Roque de Minas, Vargem Bonita, Delfinópolis, São João 


\section{OS DESAFIOS DA GEOGRAFIA FÍSICA NA FRONTEIRA DO CONHECIMENTO \\ Instituto de Geociências - Unicamp \\ Campinas - SP \\ 28 de Junho à 02 de Julho de 2017}

Batista do Glória e Capitólio. Da área supramencionada, quase $720 \mathrm{~km}^{2}$ estão sob posse e domínio do Ibama e o restante, são propriedades ainda não desapropriadas e regularizadas (IBAMA, 2005).

O PNSC é uma área de grande importância para a dinâmica hidrológica a nível regional. A serra se configura como "dispersor de drenagem" (FERREIRA, 2010), ou seja, um divisor de águas na plataforma brasileira, pois é interflúvio das bacias hidrográficas do rio São Francisco (drenando para norte) e Paraná (drenando para sul). O estudo se concentra nas áreas de topo (1500 metros de altitude), no Chapadão do Diamante.

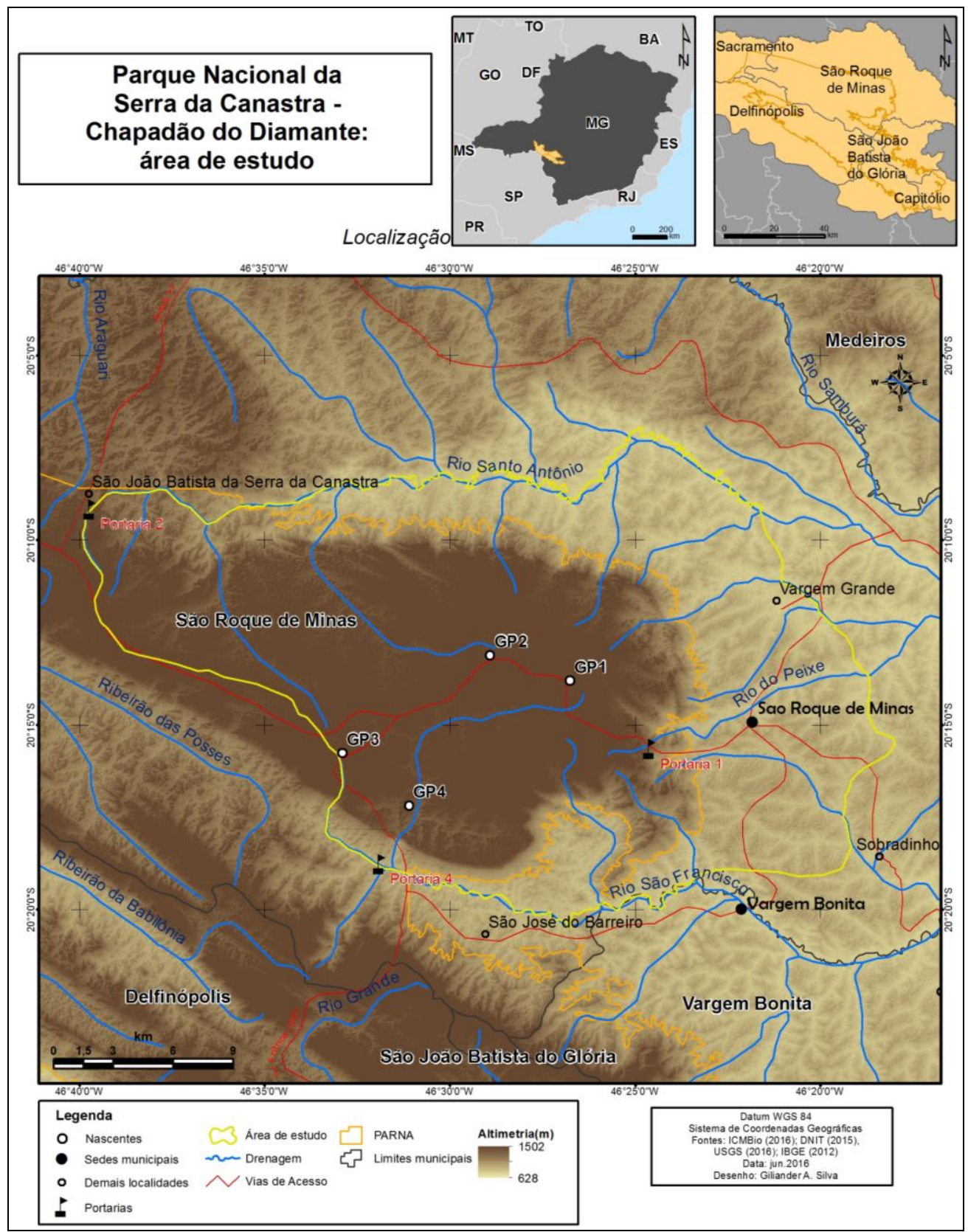

Figura 1 - Mapa de Localização da área em estudo e nascentes pesquisadas. Fonte: próprio autor, 2017. 
Sabe-se que os processos hidrogeomorfológicos desempenham importante papel na constituição de ambientes de afloramente de água e atuam/alteram (n)o relevo e $n(a)$ hidrologia. Desta maneira o estudo objetivou compreender a dinâmica das nascentes naturais a partir de análises empírica e ensaios em campo. Desta forma, o trabalho apresenta resultados iniciais de uma pesquisa, consistindo na caracterização de quatro nascentes, quanto às suas formas, tipos de exfiltração, situação de cobertura vegetal, vazão e magnitude.

\section{Referencial teórico}

A água no nosso planeta é inclusa em um sistema de circulação fechado, impulsionado pela energia solar, denominado Ciclo da Água (TUCCI, 2012; TUNDISI; MATSUMURA-TUNDISI, 2011). As variações das condições climáticas ocorridas mais recentemente, têm impactado na distribuição desta água, seja na forma líquida, sólida ou gasosa.

O volume de água doce do planeta Terra é muito pequeno se comparado à água salgada, apenas $3 \%$. Deste montante, somente $15 \%$ está disponível para a população, já que o restante está na forma de calotas polares (TUNDISI; MATSUMURA-TUNDISI, 2011).

Existem fatores do meio físico em nosso planeta que possuem função primordial para a dinâmica da água, especialmente por terem capacidades, como: armazenar, aprisionar, filtrar, disponibilizar, verter, dentre outras. Para tanto, apropria-se do conceito de Hidrogeomorfologia. Conforme pressupostos de Sidle e Onda (2004), esta ciência trata de processos hidrológicos e geomorfológicos. Sua interdisciplinaridade torna-a capaz de verificar as interações dos processos geomorfológicos com as águas subsuperficiais e superficiais.

Babar (2005) utiliza a etimologia para sintetizar que a Hidrogeomorfologia, em seus estudos, aborda a água (superficial e subterrânea), a terra e as formas da paisagem. Em outras palavras, em quais condições hidrológicas tem evoluído determinada paisagem, no âmbito de suas formas.

Neste âmbito, a Serra da Canastra se torna uma área mister para pesquisas, pois, sua complexidade geológica e características geomorfológicas (IBAMA, 2005) confere a área importância singular para a dinâmica das águas superficiais e subsuperficiais, sendo que, estas últimas são de grande expressão em regiões úmidas (SAYAMA et al., 2011).

A Serra da Canastra se configura num arranjo geológico estrutural bastante complexo. Em toda a região foram mapeados o Grupo Araxá, Grupo Canastra e Grupo Bambuí, pré-cambricos, e Bambuí, mesozoico. $\mathrm{Na}$ área de estudo ocorre o Grupo Canastra, que se estende, dentre outras áreas, no topo do Chapadão do 
Diamante, coberturas detrito-lateríticas que ocorrem pontualmente neste mesmo local e, Grupo Bambuí, mapeado nas partes rebaixadas, adjacentes à serra (LUIZ; CARNEIRO; ANDRADE, 2008; MESSIAS, 2014).

Chaves et. al. (2008) consideram que a Serra tem marcas de forte cavalgamento resultando em transporte de Sudoeste para Nordeste. Braun e Baptista (1978) apud (VASCONCELOS et al., 2010) defendem que a gênese da serra se deu pelo soerguimento de blocos por falhamento inverso, com reativações transcorrentes.

No Grupo Canastra são identificadas intercalações com espessuras variáveis de filitos e quartzitos, cuja espessura máxima pode chegar a 2000 metros. No seu conjunto, embasa-se por filitos, com presença arenosa para o topo, passando por quartzo-filitos, quartzitos micáceos, quartizos e ortoquartzitos, que são responsáveis pela sustentação das escarpas serranas e das chapadas. Compõem o Grupo Bambuí os argilitos, siltitos, calcários e conglomerados, bordejando a face nordeste do Chapadão do Diamante (PEREIRA et al., 2013).

Havendo relação direta da estrutura com o relevo, Ross (1985) argumenta que a Serra da Canastra é uma serra residual, associada aos dobramentos da Faixa Brasília. Especificamente na área em estudo, configuram-se os planaltos da Serra da Canastra, o qual apresenta duas unidades: Serras da Canastra e Patamares da Canastra. A primeira encontra-se emoldurada pela segunda unidade, a qual apresenta duas subunidades (setor norte - mais elevada - e setor sul -mais rebaixada). Nas porções de topo, onde ocorrem a unidade Serras da Canastra, os quartzitos apresentam descontinuidades em relação aos filitos, que favorecem o encaixamento da drenagem (MESSIAS, 2014).

O processo de infiltração é indispensável para que possa surgir nascentes. Entende-se infiltração como o processo de entrada de água no perfil de um material consolidado ou inconsolidado (NISHIYAMA, 1998). Por meio deste, há uma substituição do ar presente no solo pela água, tornando-o saturado. Por processos de vertente, esta água reabastece os canais no fundo do vale ou são exfiltradas na superfície.

Conhecer a quantidade de água que pode infiltrar no solo em um episódio de chuva pode fornecer importantes informações a respeito do volume de água a ser disponibilizada para os cursos d'água e meios exfiltrantes. A exfiltração é o processo inverso da infiltração, pois, trata-se da saída de água dos meios saturados do solo. Ela marca a passagem da água subterrânea ou subsuperficial para o meio superficial, formando as nascentes, contribuindo para os fluxos dos canais em associação com as águas pluviais (SILVA; NETO; SANTOS SILVA, 2014). 
As atividades humanas alcançam, nos dias de hoje, grande capacidade em condicionar processos morfodinâmicos, sendo o homem tratado como agente modelador da paisagem (SIMON; CUNHA, 2008). Contudo, há elementos discutidos pela Hidrogeomorfologia que são muito vulneráveis às atividades antrópicas, como as nascentes.

Felippe (2009) enfatiza que o conceito de nascente não tem definição muito precisa. Segundo o autor, os substantivos empregados em diversas línguas estrangeiras, na tradução literal remete ao termo "fonte", que não é sinônimo de nascente em português. Desta maneira, somente na língua portuguesa é possível diferenciar nascente de fonte, surgência ou manancial.

No Brasil, oficialmente, conceitua-se as nascentes pela Resolução CONAMA n 303/2002. Esta afirma que nascente é um "local onde aflora naturalmente, mesmo que de forma intermitente, a água subterrânea" (BRASIL, 2002).

No momento em que o homem altera os processos geomorfológicos, isso pode culminar com a exfiltração de água subterrânea e subsuperficial em locais onde este processo não ocorreria naturalmente. Neste sentido, conceituam-se as nascentes antropogênicas, que são caracterizadas pelos fluxos de água superficial originados pela exfiltração de água por conta da intervenção humana no fluxo subsuperficial (FELIPPE et al., 2014).

\section{Procedimentos metodológicos}

Para se chegar aos objetivos propostos, os trabalhos de campo estão seguindo uma programação que prioriza as visitas em campo nas quatro estações do ano. Desta maneira, estão sendo realizadas campanhas de campo na estação seca e na estação chuvosa (NOVAIS, 2011). Os resultados apresentados neste estudo, remontam desdobramentos do primeiro trabalho de campo efetivo na pesquisa, realizado no fim do mês de janeiro de 2017 .

Dentre os procedimentos metodológicos, o inicial é tomar os pontos das nascentes com um GPS de navegação. Este aparelho possibilita armazenar, além das coordenadas geográficas do ponto, os valores altimétricos, que podem ser uteis para correlações com a geologia e materiais superficiais na vertente.

A tomada de fotografias é outro processo indispensável neste estudo. Esta consiste em capturar imagens das nascentes, em solo e aéreas. Na superfície as fotos são feitas (normais e panorâmicas) com máquina fotográfica convencional, e, no ar, utilizam-se um drone (DJI Phantom 3 Standard) com câmera de 12 megapixels acoplada. 
Anotações empíricas da vegetação, litologia e materiais superficiais são realizadas na ficha de campo. Esta consiste na tomada de informações organizadas por pontos de análise e facilita a qualificação de cada nascente, uma vez que favorece a distinção das mesmas pelas descrições das condições da cobertura vegetal, do tipo de rocha presente e situação em que se encontra no relevo e da profundidade e textura relativa dos materiais superficiais. Para a litologia e cobertura de superfície também se utiliza o trado.

Ainda na Ficha de Campo são observadas outras características das nascentes. Com base em Felippe (2009) a morfologia das nascentes e os tipos de exfiltração são importantes parâmetros para distinguir e caracterizar as nascentes. Em suas pesquisas o autor apresenta sete tipos de formas: nascentes em concavidade, duto, afloramentos, talvegue, olho, cavidade e intervenção, embora destaque que novas morfologias podem acontecer. Se tratando da exfiltração, o autor expõe três tipos de nascentes: pontuais, difusas e múltiplas.

A vazão é outro parâmetro analisado nas nascentes. A partir da medição do volume de água que escoa a partir de um sistema de exfiltração, torna-se possível diferenciar as nascentes e classifica-las conforme a sua magnitude. Desta maneira, a tabela I apresenta a classificação apresentada por Meinzer (1927).

Tabela I - Classificação de nascentes em magnitude pela vazão, segundo Meinzer (1927).

\begin{tabular}{cc}
\hline Magnitude & Vazão $(\mathbf{L} / \mathbf{s})$ \\
\hline $1^{\text {a }}$ & $>2.800 \mathrm{~L} / \mathrm{s}$ \\
$2^{\text {a }}$ & 280 a $2.800 \mathrm{~L} / \mathrm{s}$ \\
$3^{\text {a }}$ & 28 a $280 \mathrm{~L} / \mathrm{s}$ \\
$4^{\text {a }}$ & 6,3 a $28 \mathrm{~L} / \mathrm{s}$ \\
$5^{\text {a }}$ & $0,63 \mathrm{a} 6,3 \mathrm{~L} / \mathrm{s}$ \\
$6^{\text {a }}$ & 63 a $630 \mathrm{~mL} / \mathrm{s}$ \\
$7^{\text {a }}$ & 8 a $63 \mathrm{~mL} / \mathrm{s}$ \\
$8^{\text {a }}$ & $<8 \mathrm{~mL} / \mathrm{s}$ \\
Magnitude 0 & sem vazão (fluxo pretérito) \\
\hline
\end{tabular}

Fonte: Adaptado de (FELIPPE, 2009).

\section{Resultados e Discussões}

O trabalho campo possibilitou levantar informações iniciais sobre as nascentes em questão. É possível avaliar distinção entre as quatro nascentes, e, novas etapas de trabalhos de campo possibilitarão análises mais detalhadas, gerando um panorama mais completo das mesmas.

O conjunto de exfiltrações que formam a nascente GP1 situa-se a dois metros do interflúvio, na alta vertente, com cota altimétrica de 1439 metros. A diferenciação por cor mais escura, também destacada pelos quadros vermelhos na Figura 2, mostra que há pelo menos dois pontos de exfiltração nesta nascente. 

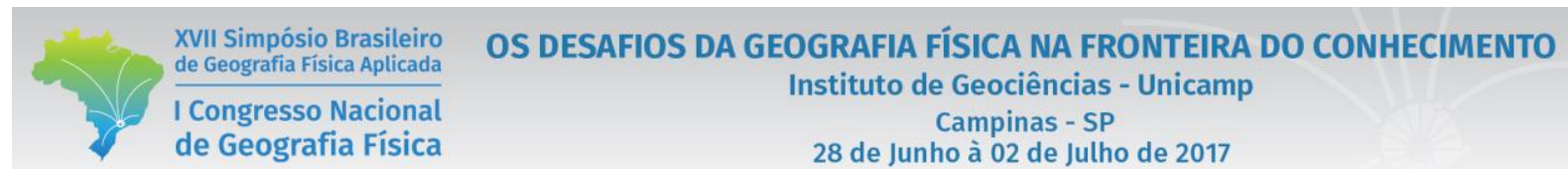

Sua ocorrência se dá na estrada, em meio a uma ruptura de declive acentuada com exposição de rochas quartzíticas ao longo de toda a vertente. O material inconsolidado é bastante delgado, sendo inexistente em alguns pontos, já que a manutenção da estrada consiste na remoção deste material, em alguns pontos, ao passo que, à jusante da nascente, usa-se blocos de rochas para cobrir as ravinas promovidas pelo fluxo concentrado da água exfiltrada, facilitando a passagem de veículos. A vegetação circundante da área é tipo campo rupestre. Em termos morfológicos, classifica-se como uma nascente de afloramento e, o tipo de exfiltração observado é múltiplo, pela variedade de pontos de saída de água na superfície. A vazão média é de $6,2 \mathrm{~mL} / \mathrm{s}$, caracterizando uma nascente de oitava magnitude.

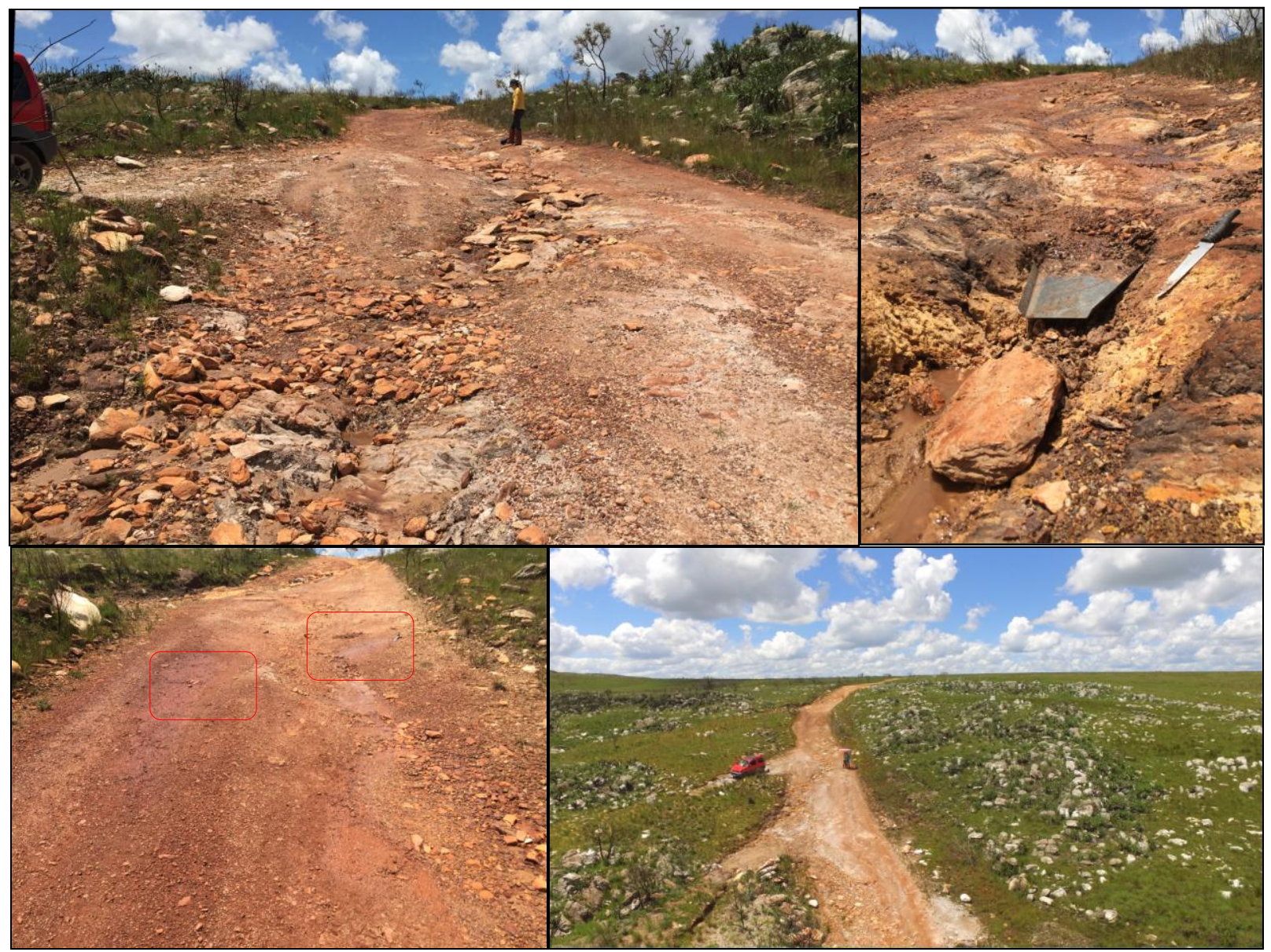

Figura 2 - Nascente GP1: ravina na estrada causada pelo fluxo d'água; medição de vazão com ajuda da calha; pontos de exfiltração na estrada; visão geral da área. Fonte: próprio autor, 2017.

A nascente GP2 situa-se a 1437 metros de altitude a aproximadamente 1 metro abaixo do interflúvio, destacado pela estrada. Pode-se observar na Figura 3, que a vegetação da área se encontra em processo avançado de recomposição devido à queimada decorrente de dois meses anteriores ao trabalho de campo e os índices pluviométricos favoreceram a revegetação. Perfurações com o trado, análise tátil e visual possibilitaram avaliar que à montante da nascente ocorre um material superficial de aproximadamente 


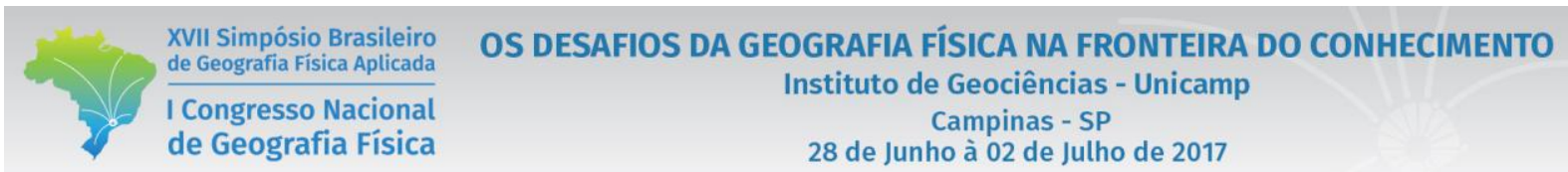

$20 \mathrm{~cm}$, sobreposto a uma couraça ferruginosa com espessura variável, cerca de $15 \mathrm{~cm}$. No interior da nascente, o material inconsolidado alcança profundidade de $40 \mathrm{~cm}$ até alcançar quartzito em estágio de saprolítico. Análises iniciais sugerem que os fluxos múltiplos em subsuperfície, abaixo da camada laterítica, tem favorecido o avanço da nascente à montante, inclusive com formações de alcovas e abatimentos. É importante destacar a grande variedade de formas que as nascentes podem apresentar. Dentre as morfologias apresentadas em (FELIPPE, 2009), embora algumas se assemelham, nenhuma representa, em essência, a nascente em questão . Desta maneira, adotar-se-á o termo nascente de erosão associada com abatimento para que, os desdobramentos futuros desta pesquisa, possa melhor descrever e exemplificar esta morfologia. Dentre as quatro nascentes estudadas, esta é a que apresentou maiores valores de vazão, $55,3 \mathrm{~mL} / \mathrm{s}$, caracterizada como uma nascente de sétima magnitude.

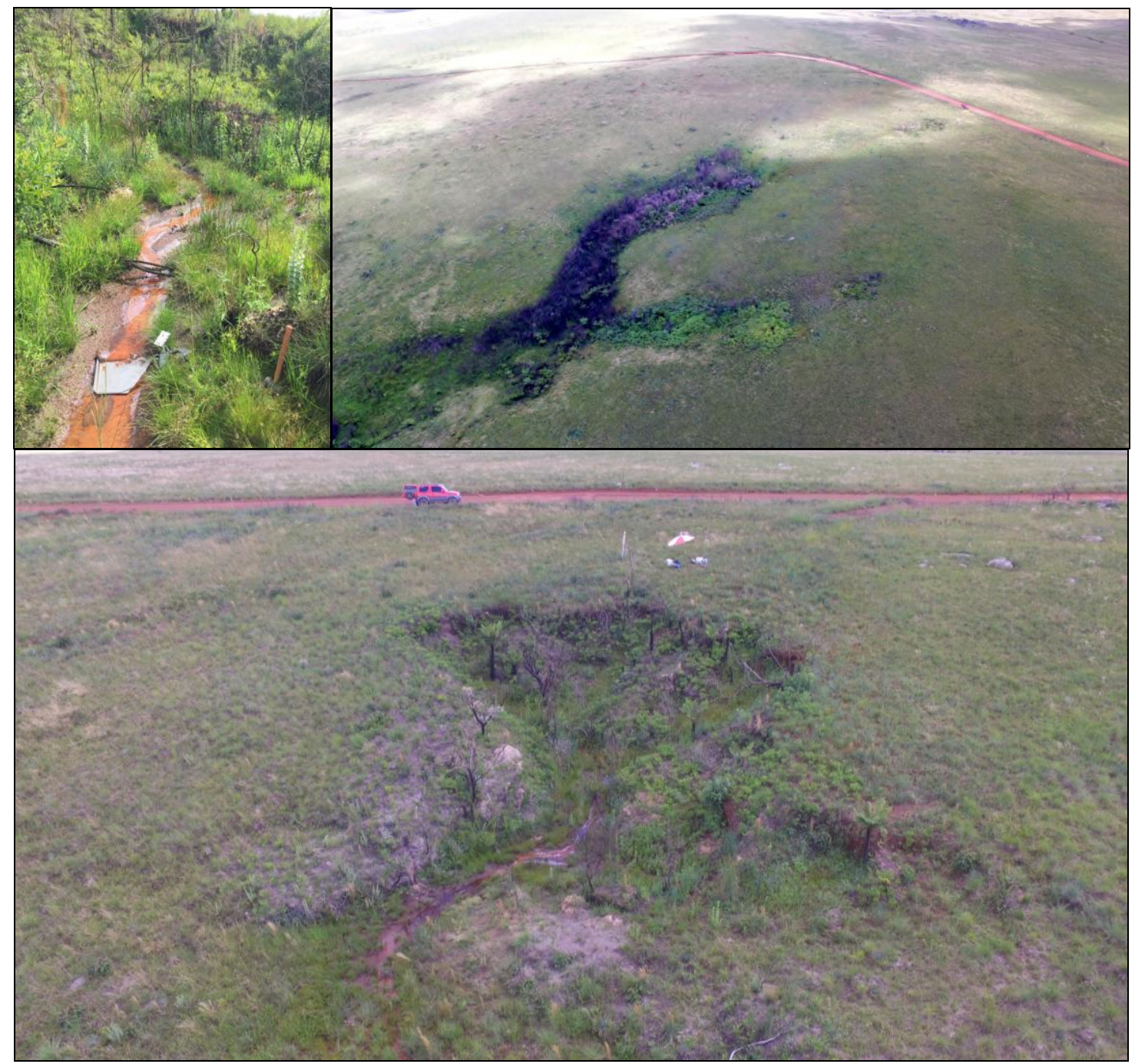

Figura 3 - Nascente GP2: medição de vazão com a calha; visão aérea lateral da nascente e à jusante; visão aérea frontal da nascente. Fonte: próprio autor, 2017. 


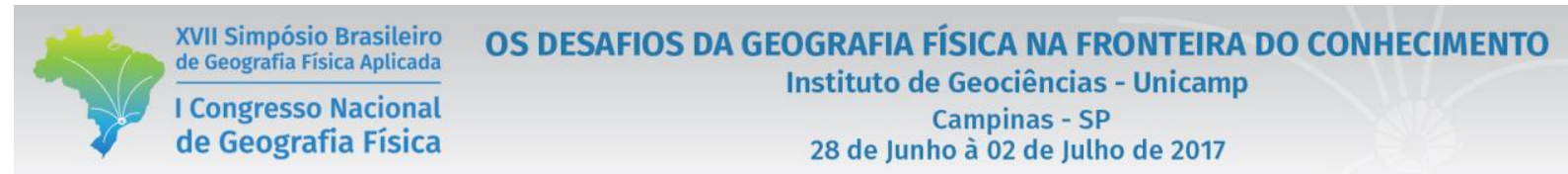

A nascente GP3 surge sob a cota altimétrica de 1415 metros. Em visita realizada no mês de novembro de 2016, a região estava com a cobertura vegetal queimada, porém, no período do trabalho de campo, toda a área se encontrava revigorada. Ao observar a Figura 4 é possível notar manchas claras na fotografia aérea, que representam os afloramentos dos quartzitos ao longo da vertente. A geologia complexa da região, devido a processos de falhamento por empurrão favorece o surgimento destes afloramentos em diversos pontos e sob variadas cotas altimétricas, não mantendo certa regularidade de ocorrência. Desta forma, nesta área de exfiltração foi possível notar um material inconsolidado bastante delgado, sempre vinculado aos afloramentos de rochas, os quais condicionam a morfologia da nascente. Entretanto, se deve atentar para a caracterização das formas já que estas podem coexistir, uma vez que as exfiltrações difusas se encontram num trecho côncavo da vertente, podendo também ser caracterizada como: de concavidade. O volume de água produzido pela nascente tem possibilitado o estabelecimento de uma vegetação arbórea à jusante. A vazão medida foi de $29 \mathrm{~mL} / \mathrm{s}$, sendo de sétima magnitude.

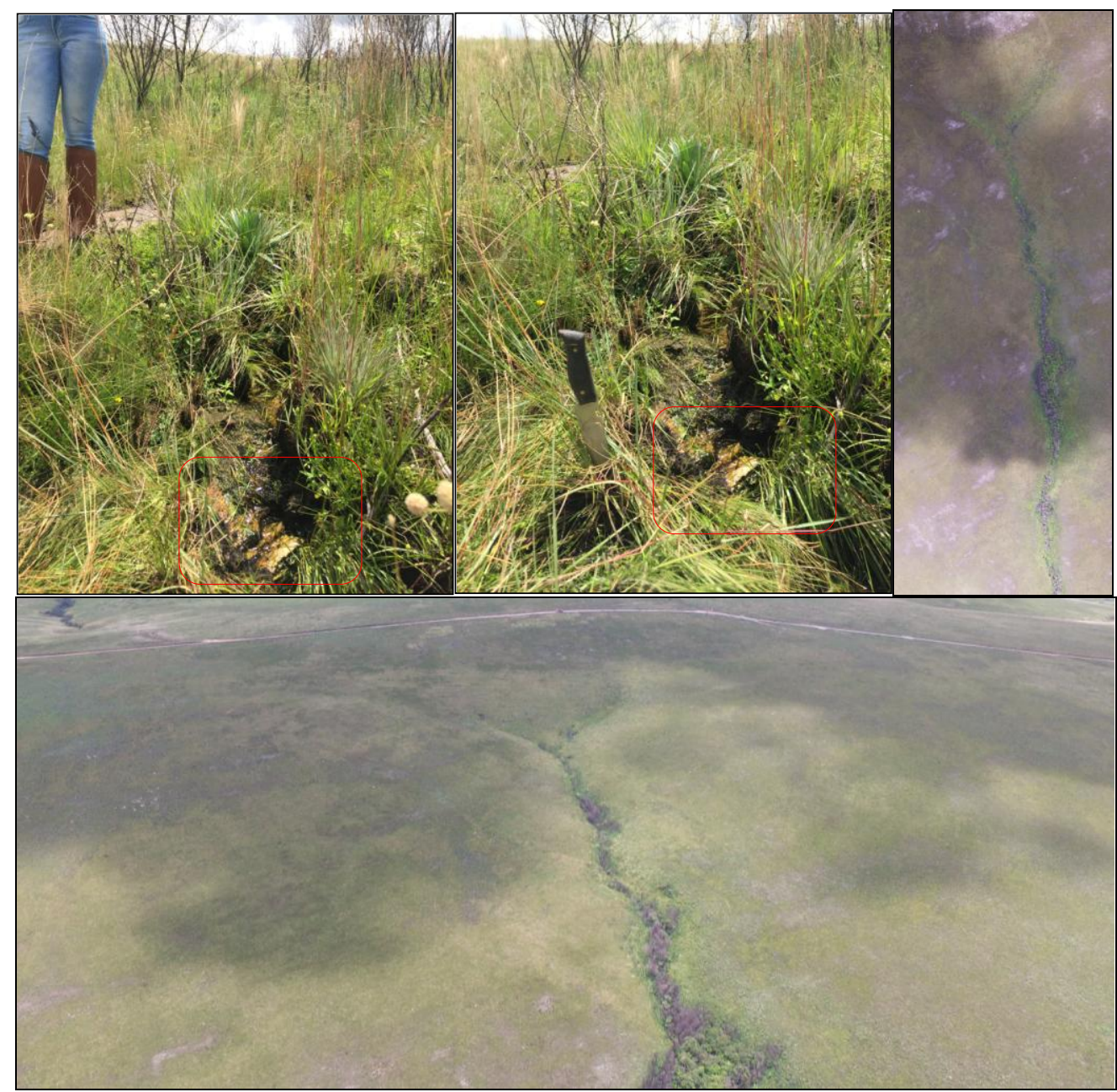

Figura 4 - Nascente GP3: afloramento de quartzito na nascente; visão aérea do canal; visão aérea frontal da área da nascente. Fonte: próprio autor, 2017. 


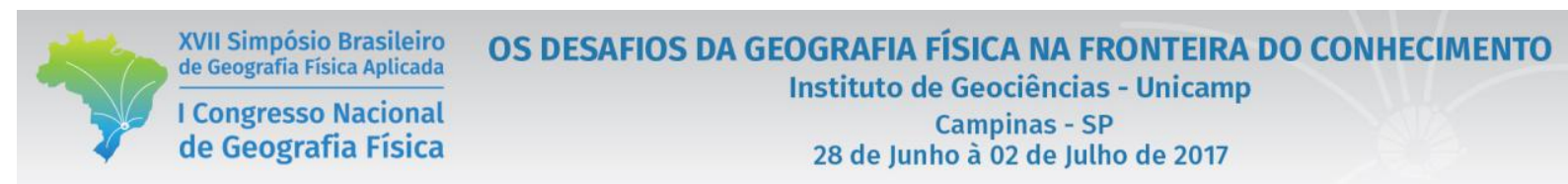

A nascente GP4 se encontra sob a cota de 1283 metros de altitude, estando no alto da vertente mais inclinada no estudo, próximo à estrada. Nota-se pela Figura 5 que a cobertura vegetal é bem estabelecida, excetuando as áreas em que ocorrem os afloramentos de rochas quartzíticas, onde o material superficial arenoso é bastante delgado, sobretudo nas áreas com manchas claras, na fotografia aérea. Observa-se ainda que a fotografia aérea foi importante para notar que há uma grande interferência das práticas de manutenção da estrada na nascente, já que, em solo a vegetação mascara tal fator. Em termos morfológicos esta nascente é classificada como de afloramento, uma vez que os fluxos múltiplos se iniciam em pleno contato do material superficial com a rocha aflorante, porém, estes fluxos produzem uma ravina que catalisa o processo de exfiltração pela interceptação do nível freático à jusante. Esta nascente é de sétima magnitude, com vazão média de $39,5 \mathrm{~mL} / \mathrm{s}$.

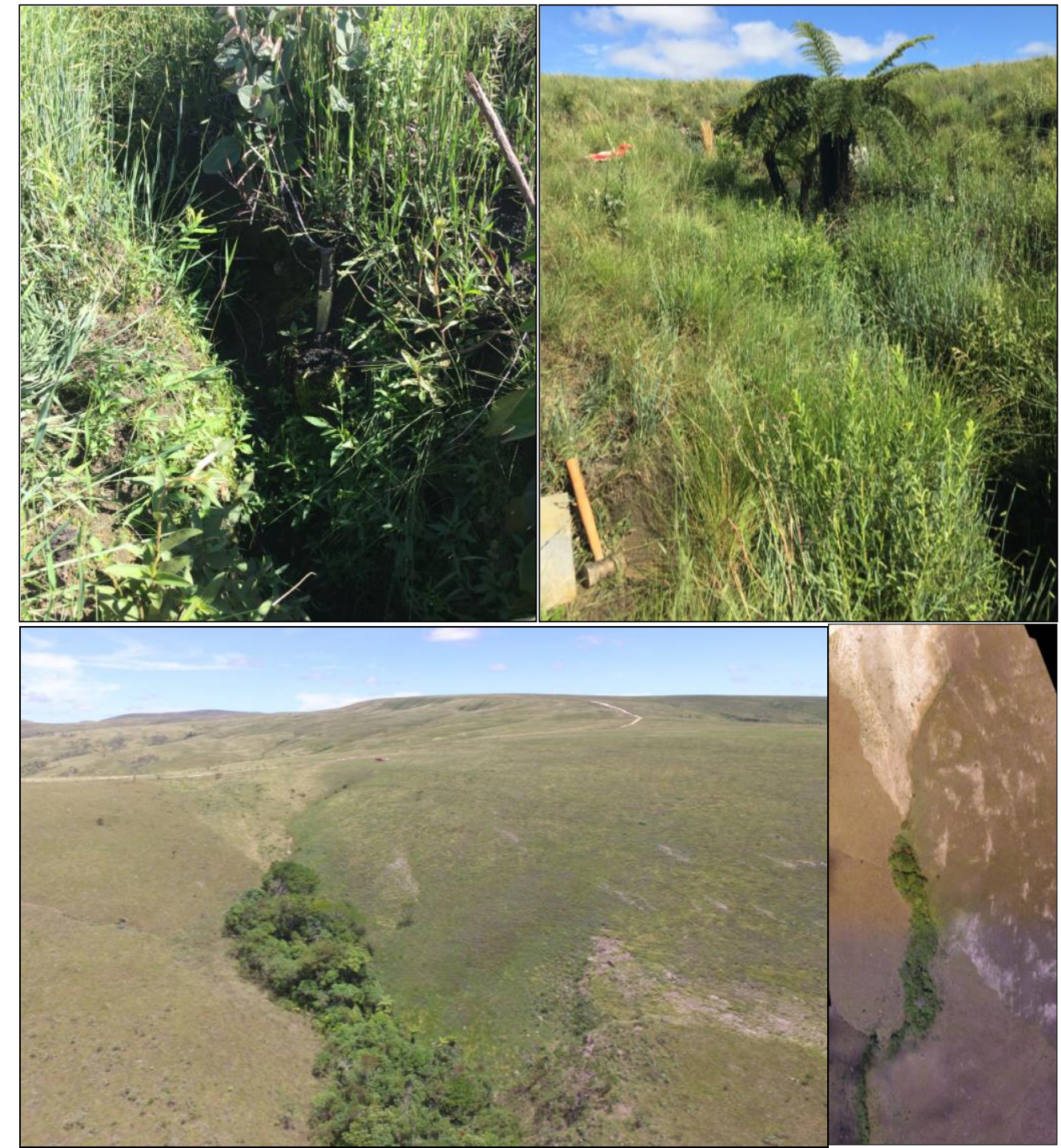

Figura 5 - Nascente GP4: local de medição da vazão; visão aérea frontal da nascente; visão aérea do canal. Fonte: próprio autor, 2017. 


\section{Considerações}

Definir a morfologia de uma nascente é uma tarefa complexa, por mais de uma forma pode coexistir, além das nascentes serem mutáveis de forma e local conforme o regime pluviométrico. $\mathrm{O}$ uso de equipamentos que possibilitam capturar fotos aéreas auxilia bastante para localizar nascentes, identificar os fluxos, pontos exfiltrantes e definir as formas das mesmas. No entanto, as nascentes são elementos de extrema importância para a dinâmica hidrológica e por isso, precisam de muito estudo, sobretudo no clima tropical que favorece grandemente o processo de infiltração de água nos materiais superficiais.

\section{Bibliografia}

BABAR, M. Hydrogeomorphology: Fundamentals, Applications and Techniques. New Delhi: New India Publishing, 2005.

BRASIL. Resolução CONAMA n 303. de 20 de março de 2002. Ministério do Meio Ambiente. 2002.

CHAVES, M. L. DE S. C. et al. Kimberlito Canastra-1 (São Roque de Minas, MG): geologia, mineralogia e reservas diamantíferas. Revista da Escola de Minas, v. 61, n. 3, p. 357-364, 2008.

FELIPPE, M. F. Caracterização e tipologia de nascentes em unidades de conservação de Belo Horizonte-MG com base em variáveis geomorfológicas, hidrológicas e ambientais. Dissertção (mestrado em Geografia e Análise Ambiental)-Belo Horizonte: Universidade Federal de Minas Gerais, 2009.

FELIPPE, M. F. et al. Nascentes antropogênicas: processos tecnogênicos e hidrogeomorfológicos. Revista Brasileira de Geomorfologia, v. 14, n. 4, p. 279-286, abr. 2014.

FERREIRA, M. M. DE S. Avaliação da qualidade da água subterrânea para consumo humano na bacia do Rio São Bartolomeu: o caso dos poços tubulares profundos do Setor Habitacional Jardim Botânico, Distrito Federal. Dissertação de Mestrado-Brasília: Universidade de Brasília, 2010.

GOERL, R. F.; KOBIYAMA, M.; SANTOS, I. D. Hidrogeomorfologia: princípios, conceitos, processos e aplicações. Revista Brasileira de Geomorfologia, v. 13, n. 2, p. 103-111, 2012.

IBAMA. Plano de Manejo do Parque Nacional da Serra da Canastra. Resumo Executivo. p. 104-104, 2005.

LUIZ, M.; CARNEIRO, D. S.; ANDRADE, K. W. Província diamantífera da Serra da Canastra e o kimberlito Canastra-1: primeira fonte primária. Geociências, v. 27, p. 299-317, 2008.

MESSIAS, C. G. Mapeamento das áreas suscetíveis à fragilidade ambiental na Alta Bacia Do Rio São Francisco, Parque Nacional da Serra da Canastra - MG. Dissertação (mestrado em Geografia) —Campinas: Universidade Estadual de Campinas, 2014.

NISHIYAMA, L. Procedimentos de mapeamento geotécnico como base para análise e avaliações ambientais do meio físico em escala 1: 100.000 aplicação no município de Uberlândia-MG. Tese (doutorado em Geotecnia)São Carlos: Universidade de São Paulo, 1998.

NOVAIS, G. T. Caracterização climática da mesorregião do Triângulo Mineiro/Alto Paranaíba e do entorno da Serra da Canastra (MG). Dissertação (mestrado em Geografia)-Uberlândia: Universidade Federal de Uberlândia, 2011.

PEREIRA, L. F. et al. Evolução geológica dos grupos Canastra e Ibiá na região entre Coromandel e Guarda-Mor, MG. Revista Geonomos, v. 2, n. 1, 2013.

ROSS, J. L. S. Relevo brasileiro: uma nova proposta de classificação. Revista do Departamento de Geografia, v. 4, p. 25-39, 1985. 
SAYAMA, T. et al. How much water can a watershed store? Hydrological Processes, v. 25, n. 25, p. 3899-3908, 2011.

SIDLE, R. C.; ONDA, Y. Hydrogeomorphology: overview of an emerging science. Hydrological Processes, v. 18, n. 4, p. 597-602, mar. 2004.

SILVA, A. P. L.; NETO, J. V. F.; SANTOS SILVA, J. H. Estudo da vazão hídrica nas nascentes da Serra da Caiçara, município de Maravilha-Alagoas. Reflexões e Práticas Geográficas, v. 1, n. 1, p. 82-92, 2014.

SIMON, A. L. H.; CUNHA, C. M. L. Alterações geomorfológicas derivadas da intervenção de atividades antrópicas: Análise temporal na Bacia do Arroio Santa Bárbara-Pelotas (RS). Revista Brasileira de Geomorfologia, v. 9, n. 2, 2008.

TUCCI, C. E. Hidrologia: ciência e aplicação. Porto Alegre: Editora UFRGS, 2012.

TUNDISI, J. G.; MATSUMURA-TUNDISI, T. Recursos hídricos no século XXI. São Paulo: Oficina de Textos, 2011.

VASCONCELOS, V. et al. Caracterização de uma Topossequência no Parque Nacional da Serra da Canastra, MG.

Boletim de Pesquisa e Desenvolvimento - Embrapa Cerrados, n. 277, 2010.

\section{Agradecimentos}

Agradecemos a FAPEMIG pelo apoio à participação no XVII SBGFA, também por meio do projeto CRA APQ-00231-16 pelo apoio à realização da pesquisa. 